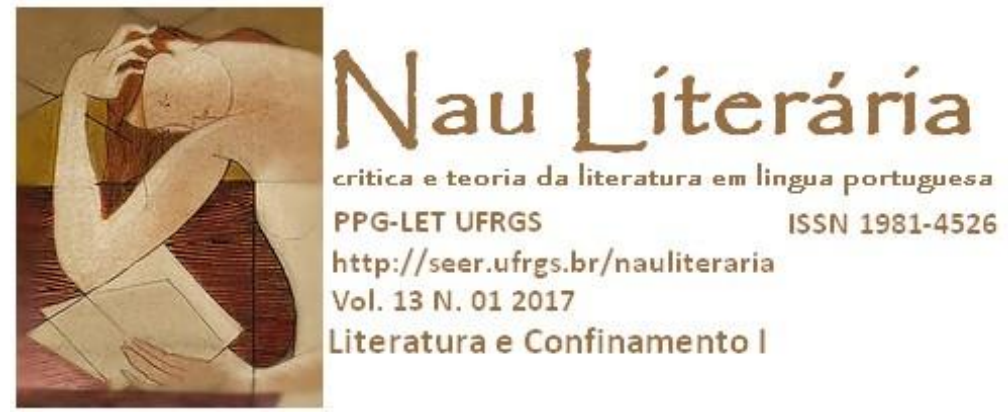

\title{
Graciliano Ramos e os bilhetes do cárcere: considerações a respeito dos escritos da prisão
}

Cicera Jessiane Lins dos Santos

\begin{abstract}
Resumo: Neste trabalho, propõe-se um olhar para os escritos não pretensamente artísticos de Graciliano Ramos, com destaque para os bilhetes enviados a Heloísa Ramos durante o encarceramento do escritor, a fim de abrir a discussão sobre as possíveis contribuições desses textos em releituras da obra do romancista em uma dada conjuntura artística, política e social. Para isso, recorremos às considerações de Geneviève Haroche-Bouzinac em seu livro Escritas epistolares, em que trata dos bilhetes como forma que descende da carta.
\end{abstract}

Palavras-chave: bilhetes; epistolografia; Graciliano Ramos.

\begin{abstract}
In this work, we propose a look at Graciliano Ramos' non-pretentious writings, especially the notes sent to Heloísa Ramos during the imprisonment of the writer, in order to raise a discussion about the possible contributions of these texts in re-readings of the work of Novelist in a given artistic, political and social context. For this purpose, we turn to Geneviève Haroche-Bouzinac's considerations in his book Escritas epistolares, which approaches notes as a form of letter.
\end{abstract}

Keywords: notes; epistolography; Graciliano Ramos.

Ao tratar de literatura, sua e de seu tempo, Graciliano Ramos expressou, em entrevistas, artigos de crítica, contos, crônicas, já em Caetés e também em suas cartas, um critério de valor que se traduz na indissociação entre a arte e a sociedade, chegando a asseverar, por modéstia ou por autodepreciação, limitação criativa ao deter-se no experienciado, nas lembranças, no que era seu. Em Memórias do cárcere (1953), mostrou-se admirado por José Lins do Rego conseguir suplantar essas fronteiras. Referindo-se ao romance $O$ moleque Ricardo (1935), o romancista alagoano questionou-se se o seu autor conheceria a vida: "Que entendia ele de meninos nascidos e criados na lama e na miséria, ele, filho de proprietários? Contudo a narração tinha verossimilhança. Eu seria incapaz de semelhante proeza" (RAMOS, s.d., vol. 1, p. 44), pois só se "abalançava" a "expor a coisa observada e sentida" (RAMOS, s.d., vol. 1, p. 44), como se esse aspecto já não fosse amplo 
pela complexidade que encerra, e como se o escritor retratasse tão só a reportagem do vivido, algo que não fez.

A necessidade de fixação da realidade não foi declarada apenas pela voz de Graciliano Ramos. Em Ficção e confissão, Antonio Candido apresentou uma trajetória em direção à acentuação do factual na obra do escritor. No primeiro livro, publicado em 1933, está a cidade do interior, no segundo, de 1934, o referente político e social, em Angústia (1936), alguns delírios aproveitados de outros tempos, em Vidas secas (1938) estariam reconfigurados os avós e os tios, conforme se lê em carta de Graciliano ao jornalista João Condé, em junho de 1944: "Transformei o velho Pedro Ferro, meu avô, no vaqueiro Fabiano; minha avó tomou a figura de Sinhá Vitória; meus tios pequenos, machos e fêmeas, reduziram-se a dois meninos" (Arquivo IEB-USP Fundo GR-CA-06). A seguir, há as recordações declaradas em Infância (1945) e nas Memórias do cárcere (1953). E em todos os romances, a atenção voltada para o sujeito e não apenas para as feições regionais ou sociais como um todo.

Nesses trabalhos, o escritor parece ter processado os fatos "aproveitados", mas em outros esteve submetido ao calor da hora e aos limites impostos às suas declarações. De acordo com os relatos das Memórias, alguns desses escritos foram descartados em virtude das inconveniências que poderiam causar se descobertos ali, abordando, por exemplo, o porão do navio em que fora transportado: "Não resguardei os apontamentos obtidos em largos dias e meses de observação: num momento de aperto fui obrigado a atirá-los na água" (RAMOS, s.d. vol. 1, p. 23). As recordações, organizadas, tardaram a aparecer concretizadas em livro, mas é possível encontrar pistas indicando o seu projeto e um dos motivos de sua longa gestação, como se vê na carta destinada ao filho Júnio Ramos em 12 de outubro de 1945:

\footnotetext{
Findos alguns compromissos neste resto de ano, iniciarei um trabalho a respeito das prisões de 1936. É difícil e arriscado: tenciono apresentar aquela gente em cuecas, sem muitos disfarces, com os nomes verdadeiros. Necessito a autorização das personagens: não tenho o direito de utilizar gente viva num livro de memórias que encerrará inconveniências. Preciso falar sério com meus companheiros de cadeia. Se fizer o livro, poderei publicá-lo no jornal de Santos, antes de entrega-lo ao editor. Mandarei os capítulos à medida que forem sendo feitos. Foi o que fiz com Infância. (RAMOS, 2011, p. 285)
}

Há dois pontos que se destacam nesse processo: a quantidade de trabalho, a que o escritor não pôde se dar ao luxo de interromper, e as prováveis polêmicas que revelações contundentes, especialmente quando se empreende uma tentativa de aproximação da objetividade, "sem muitos disfarces", poderiam levantar, naquela altura, para o seu autor e 
para aqueles com quem estivera, do mesmo lado ou do lado oposto. Memórias do cárcere, pelo seu "quando", “o quê", "onde", "como", "por quê" e pela forma como responde a essas questões, se destaca ainda hoje entre as obras que carregam o registro de um tempo convulsionado social e politicamente, todavia não é o único elo do romancista com os tempos da prisão.

Um conto publicado pouco tempo depois da libertação de Graciliano Ramos: "Um ladrão", reconfigura as narrativas de Gaúcho, com quem o escritor manteve amizade durante o encarceramento. Nessa ficção, o autor traz, sob outra perspectiva, um episódio de assalto malogrado, que lhe fora contado pelo amigo. Além disso, existem os bilhetes da prisão sobre os quais nos debruçaremos - coligidos no primeiro volume de missivas íntimas de Graciliano, Cartas, publicado em 1980.

Nas correspondências dessa reunião, e em outras pertencentes ao arquivo do escritor no Instituto de Estudos Brasileiros da Universidade de São Paulo, é possível encontrar declarações relativas à literatura brasileira, aos movimentos artísticos destacados entre as décadas de 20 e 30 e à situação política e social do país, assuntos por vezes tratados em integração. Já os bilhetes chamam a atenção pelo seu discurso, no sentido de este se diferenciar consideravelmente daquele empregado nas cartas, mesmo que para o mesmo interlocutor. Destacam-se igualmente pela maneira como apresentam as informações: comedidas, limitadas, ao que parece, pela interferência de leitores não destinatários.

Os bilhetes fizeram parte do confinamento de Graciliano Ramos. Ainda no começo, no Pavilhão dos Primários e depois na Casa de Correção, no Rio de Janeiro, ofereceram pistas de como seria a relação do romancista com os seus escritos ali, no sentido de tangenciada pela repressão, da qual dá notícias em 1953. Mesmo se tratando de uma produção não pretensamente literária e comedida, considera-se a inclusão desses pequenos textos como parte integrante de sua obra, pois eles se relacionam com outros trabalhos tidos como mais relevantes pela crítica, estabelecem diálogos com eles e sugerem muito pelo pouco que dizem materialmente.

Com isso em vista, propõe-se a discussão da posição desses breves escritos na produção de Graciliano Ramos, do impacto do contexto na organização desse gênero e do que o escrito suscita ao não dizer, comparando-os, nesse aspecto, às cartas destinadas à Heloísa Ramos. Para isso, nos direcionaremos especialmente pelas considerações da pesquisadora 
francesa Geneviève Haroche-Bouzinacem Escritas epistolares (2016), não nos detendo apenas às ponderações relativas aos bilhetes, mas também àquelas concernentes às correspondências, forma da qual esses descendem como configuração possível.

De acordo com Bouzinac, os bilhetes são formas epistolares nascidas da "vontade de escapar dos excessos da codificação" (2016, p. 46). Em Graciliano Ramos, presume-se que nascem pela impossibilidade de interlocução, alongamento e intervenção de leitores não destinatários, já que foram escritos durante a sua detenção - apenas dois encontram-se datados: um de 27/03/1936 e outro de 5 de outubro.

Deixados um pouco de lado frente à grandeza dos romances, os nove escritos, todos direcionados a Heloísa Ramos, esposa do romancista, trazem principalmente informações relativas às condições no cárcere e à sua saúde: "Encontrei aqui excelentes companheiros. Somos setenta e dois no pavilhão onde estou", "O capitão Mata é um excelente companheiro, e com ele ninguém pode estar triste", "Vou passando bem", "Vou bem de saúde, mas terrivelmente amolado", "A saúde vai bem", "De saúde passo bem”, “A saúde vai bem, mas continuo a não poder trabalhar" (RAMOS, 2011, p. 223-225), indicações naturais, próprias de um contexto sem muitos esclarecimentos, sugerindo atenção com as preocupações e inflexões do receptor.

Há também breves referências ao externo, como o interesse pela repercussão de Angústia, por exemplo: “Todos os jornais calaram-se: provavelmente o livro se esgotou. Se lhe cair nas mãos algum artigo da província, é bom guardá-lo. Quero saber o que dizem em Minas" e em outro bilhete posterior: "Se não me engano, o Angústia morreu. Um silêncio de morte" (RAMOS, 2001, p. 225). O Angústia foi publicado nesse meio, meio às pressas, em meio à ameaça, dificultando o prosseguimento do processo criativo característico de Graciliano, metaforizado em uma entrevista ao jornalista Joel Silveira, em 1938, coligida no livro Conversas (2014). Nela, o autor de São Bernardo compara a escrita à maneira como as lavadeiras de Alagoas realizam seu trabalho:

\footnotetext{
Elas começam com uma primeira lavada. Molham a roupa suja na beira da lagoa ou do riacho. Torcem o pano, molham-no novamente, voltam a torcer. Depois colocam o anil, ensaboam, e torcem uma, duas vezes. Depois enxáguam, dão mais uma molhada, agora jogando água com a mão. Depois batem o pano na laje ou na pedra limpa e dão mais uma torcida e mais outra, torcem até não pingar do pano uma só gota. Somente depois de feito tudo isso é que elas dependuram a roupa lavada na corda ou no varal, para secar. Pois quem se mete a escrever devia fazer a mesma coisa. A palavra não foi feita para enfeitar, brilhar como ouro falso, a palavra foi feita para dizer (RAMOS, 2014, p. 77).
} 
Esses passos, que se traduziriam nos cortes, eliminação de excrescências, não puderam ser seguidos na história de Luís da Silva, a prisão foi um empecilho, bem como a necessidade de publicação. É o que Ramos testemunhou a Antonio Candido depois, em 1945, em carta resposta aos ensaios escritos pelo crítico sobre a sua obra:

Forjei o livro em tempo de perturbações, mudanças, encrencas de todo o gênero, abandonandoo com ódio, retomando-o sem entusiasmo. Matei Julião Tavares em vinte e sete dias; o último capítulo, um delírio enorme, foi arranjado numa noite. Naturalmente seria indispensável recompor tudo, suprimir excrescências, cortar pelo menos a quarta parte da narrativa. A cadeia impediu-me essa operação. A 3 de março de 1936 dei o manuscrito à datilógrafa e no mesmo dia fui preso (CANDIDO, 2006, p. 11).

A velocidade compreendida nessas linhas vai de encontro ao ritmo aconselhado na entrevista de 1938 e verificado no testemunho de outras produções a que o romancista pôde, ainda que com percalços distintos, voltar-se mais demoradamente. A consequência do encurtamento dos momentos da gênese criativa teria sido o exagero, referido por Graciliano como "gordura", tal qual Candido, que caracterizou a obra como "romance excessivo", contrastante em meio a São Bernardo e Vidas secas (CANDIDO, 2006, p. 47), por certamente se embrenhar de forma mais expressiva na introspecção, sendo a ação suplantada pelos monólogos interiores.

Em carta de 13 de maio de 1937, Graciliano, ao apresentar o mesmo romance para tradução, busca, adiantando-se a críticas ou à criação de expectativas, explicar-se ao tradutor argentino Benjamin de Garay com os mesmos motivos:

Esse desgraçado livro saiu cheio de pastéis. Quando foi para composição, eu era considerado elemento perigoso e naturalmente os cavalheiros que me hospedavam não julgaram necessária a revisão das provas. Foi um desastre. Veja se consegue adivinhar o que estava no original, e se isto não for possível, espere a segunda edição, que talvez se faça. É coisa menos ruim que $S$. Bernardo (Feudo Bárbaro), penso eu (RAMOS, 2008, p. 53-54).

Nesse último trecho, notam-se, ademais dos porquês, a ironia e o pessimismo na autoavaliação, ambos, aqui e em outras cartas, dando ensejo à graça, a uma espécie de humor disfórico, diluído pela objetividade nos textos breves da prisão. Além dessas, há outras questões configuradas no discurso e no gênero, não necessariamente concretizadas pelo código, mas nele permeadas, conforme se buscará notar.

Os bilhetes e as cartas de Graciliano Ramos, de forma geral, não são como as obras artísticas que se quiseram enquanto tal, mas acompanharam-nas, paralela, retrospectiva ou prospectivamente, delineando concepções estéticas e ideológicas que permitem colorir a leitura e a releitura com outros tons. Mesmo trazendo questões significativas, esses escritos 
íntimos parecem se encontrar em outro plano, embora o cenário venha mudando com publicações e pesquisas que se direcionam para essas realizações.

Na seção “A carta, gênero menor?”, Bouzinac apresenta algumas ponderações ao longo da história que exemplificam a hierarquização dos gêneros literários, estando a carta, nesse posicionamento, geralmente distante do topo, em virtude do que seria uma limitação à sua exposição de ideias, sentimentos e informações, atividades por suposto pouco exigentes para um bom autor. Sendo o bilhete um desdobramento da carta, ele estaria consequentemente ainda mais apartado da produção prestigiada artisticamente. Sobre essas qualificações, houve exceções todavia, mas ainda assim não tão expressivas frente à força do gênero e de suas formas.

Em Orgulho de jamais aconselhar (2007), Marcos Antonio de Moraes oferece um Mário de Andrade que se aproxima a essa perspectiva, em virtude de o modernista compreender o espaço da carta "para o 'treino', o 'adestramento' da escrita, para o enfrentamento diário de problemas 'técnicos' da arte da palavra" (MORAES, 2007, p. 110), escrever cartas, nesse sentido "vale como um conselho aos novos ficcionistas, apressados divulgadores de obras imperfeitas" (MORAES, 2007, p. 111). Ambiente profícuo para a "elaboração de pensamento", tem-se na correspondência a possibilidade da experimentação, fator que poderia aproximá-la, aí sim, à obra literária pela pretensão criativa e até artística do epistológrafo. Esse acercamento poderia se dar igualmente a partir do citado acompanhamento entre escrita epistolar e produção literária, quando a primeira discorre sobre o andamento da segunda, fornecendo, nessa situação, matéria para a investigação genética, por exemplo. Seria possível encontrar nos testemunhos encerrados nesses escritos, também, o delinear de conjunturas artísticas, políticas, sociais, em um movimento de ampliação de ângulos de observação e análises, perspectiva importante em um cenário cultural no qual parte de seus artistas, com destaque para os romancistas de 30, voltava-se para o presente fraturado do país.

Nesse último aspecto, destacam-se algumas correspondências de Graciliano Ramos, pelo posicionamento discursivo em relação ao seu tempo, como se percebe, por exemplo, na correspondência enviada à esposa em 28 de janeiro de 1936, em um episódio em que o escritor a aconselhou para a composição de um romance, cuja personagem "Maria Antônia" seria central.

Pergunta-me se essa criatura deve falar como toda a gente. Está claro. Pois havia de usar linguagem diferente? Falar como as outras pessoas, sem dúvida.Foi o palavreado difícil de 
personagens sabidos demais que arrasou a antiga literatura brasileira. Literatura brasileira uma ova, que o Brasil nunca teve literatura. Vai ter de hoje em diante. E você deve trabalhar para que Maria Antônia entre nela. Veja se consegue pegar a vida dela, a do curandeiro, isso que aí deixamos assentado. [...]. Enfim tem você um excelente material, material como poucos sujeitos encontraram. (RAMOS, 2011, p. 217)

Pode-se notar aí vestígios de um espírito de época marcado, naquela altura, pela oposição a outros movimentos que, por uma determinada ótica, aparentavam se distanciar da realidade e de seu sujeito, diferentemente do que ocorre nos bilhetes. Nestes, o "o quê?" muda de tom, e até a forma de referenciar o interlocutor se distingue, as preocupações afinal eram outras: "Heloísa: vai um cheque de trezentos mil-réis. Retire o que necessita e mande-me cem mil-réis. [...] Só utilize o papel que lhe remeti há dias se for absolutamente indispensável. Vou bem de saúde. Nenhum trabalho. Abraços, Graciliano” (RAMOS, 2011, p. 224).

Na leitura das cartas anteriores ao cárcere, é possível pensar na existência de algumas constantes no estilo epistolar do romancista, como a informalidade manifesta no tratamento dos assuntos abordados, próprio da chamada carta familiar: "É necessário que me desenrosque. Por isso arranjei uma datilógrafa. Enquanto lhe escrevo, ela está aqui batendo na máquina: teco, teco, teco. Não se assuste: é uma senhora respeitável, em tipo e em idade"1; nos vocativos empregados nas referências ao interlocutor: a Heloísa dos bilhetes da prisão é a Dona Ló, Sinha Ló, Ló, Santa Ló, Lozíssima e até Lozinha del cuore nas cartas; e ainda, em certa medida, em algumas despedidas: nas cartas há "Beijos e miados. Graciliano"2, "Muitos beijos, muitos abraços, etc. Graciliano"3, "Abraços do esposo fiel Graciliano", já nos bilhetes: "Abraços para você e para todos. Beijos nos pequenos. Graciliano", "Abraços. Graciliano", "Muitos agradecimentos e abraços. Graciliano", "Lembranças aos amigos. Abraços" $"$.

Note-se que a informalidade não se estende à linguagem. Nos bilhetes, em contraposição, a formalidade parece desenvolver-se não apenas pela escrita, mas também pelo discurso como um todo. As ironias e o pessimismo teimoso se modificam, são reduzidos pela limitação do canal e pelas intervenções censoras, e mais por estas do que por aquele, já que temos o bilhete como espaço em que cabem informalidades, tanto nas matérias quanto na linguagem.

\footnotetext{
${ }^{1}$ RAMOS, 2011, p. 149.

2 RAMOS, 2011, p. 150.

${ }^{3}$ RAMOS, 2011, p. 152.

${ }^{4}$ RAMOS, 2011, p. 159, grifos do autor.

${ }^{5}$ RAMOS, 2011, p. 223-225.
} 
Embora hoje o gênero não seja concebido como uma criação estanque ou prémoldada, é de se destacar, no escritor alagoano, a força desse último aspecto em sentido de contradição à necessidade de comunicação em virtude da qual originalmente o bilhete se manifesta. "O peso das prescrições a que se submetia a carta ameaçava a sua espontaneidade" (BOUZINAC, 2016, p. 46), sendo o bilhete um espaço mais livre formalmente, porém nem sempre.

As escritas epistolares dependem de fatores relacionados à conjuntura histórica: "situação das vias e das comunicações postais, estrutura hierárquica das relações sociais [...]. Todos esses parâmetros influem no conteúdo e na forma da mensagem enviada e condicionam igualmente a sua recepção" (BOUZINAC, 2016, p. 26).

Nesse sentido, Moraes, em "Epistolografia e crítica genética", acrescenta que a missiva "encontra-se ancorada em um ponto da trajetória de vida do sujeito" e mais: "a verdade que a carta eventualmente contém - a do sujeito em determinada instância, premido por intenções e desejos - é datada, cambiante e prenhe de idiossincrasias" (MORAES, 2007, p. 32). Notamos assim os chamados aspectos fronteiriços que envolvem a correspondência, e nesse caso também os bilhetes, uma vez que podem estar entre a ficção e a verdade, o documento e a encenação, o compartilhamento e a intimidade, a construção e a desconstrução, atendendo às exigências do destinatário, daquele desejado e do possível, e às intenções do remetente.

Essas realizações e mudanças podem ser percebidas sem uma leitura comparativa. Ao lermos os bilhetes, em especial o primeiro da reunião de 1980, seria possível interpretar que o autor de Vidas secas não rechaçava a prisão e as suas condições de todo, porém, ao nos depararmos com as linhas de Memórias do cárcere ou com outros depoimentos detalhando o período e os lugares, verificamos diferenças como as seguintes.

Em bilhete de 27 de março de 1936,

Pediram-me uma conferência sobre a literatura do Nordeste, mas não tenho coragem de fazê-la. As conferências aqui são feitas de improviso, algumas admiráveis. Tudo bem. As camas têm percevejo, mas ainda não os senti. Quanto ao mais, água abundante, alimentação regular, bastante luz, bastante ar. E boas conversas, o que é melhor. Não lhe pergunto nada, porque as suas cartas não me seriam entregues. Abraços para você e para todos. Beijos nos pequenos. Graciliano. (RAMOS, 2011, p. 223)

Nas Memórias: 
Consegui tragar uns bocados. Arroz insípido, carne misturada com peixe. [...]. Na ausência de móveis, arrumei sobre o guarda-vento os livros, a valise, a roupa dobrada. E estendi-me para repousar. [...] O colchão era tão delgado que não me deixava em sossego, um varão do lastro magoava-me o espinhaço. Virei-me para um lado e para outro, avancei, recuei, e sempre a infeliz haste de metal a chocar-me os ossos. Alojei-a por fim entre as últimas costelas e o ilíaco, adormeci ouvindo a esfrega nas camisas do capitão, o esguicho da torneira. (RAMOS, s.d., p. 167)

Ambas as passagens fazem referência à breve estadia do escritor no Pavilhão dos Primários, em 1936, para onde foi transferido quando chegou ao Rio de Janeiro e após ser rejeitado em outras unidades por falta de espaço. Como observou o professor Luiz Costa Lima, “De fato, o 'pavilhão', comparado à travessia no 'Manaus', pareceria uma colônia de férias. Mas não era bem assim" (2003), como nos mostram a citada obra póstuma e a então conjuntura repressiva.

O possível atuar percebido nesse cotejo poderia passar desapercebido pelo efeito de verdade que os gêneros relacionados à escrita de si suscitam. A partir das faces que a carta e seus desdobramentos revelam e já revelaram em sua história, apreende-se esse resultado pelo caráter que o gênero assumiu, desde há muito, ao incorporar o que seria a confidência de si ao correspondente e a si mesmo, em uma ação recíproca entre escrita e redator, com toda a carga de verdade e centralização do sujeito que o termo confissão implica. Silviano Santiago, por exemplo, ao retomar o conceito de Michael Foucault, afirma ser a escrita da carta "a forma mais desinibida e sublime da "écriture de soi"” (SANTIAGO, 2006, p. 65).

Com essa perspectiva, as palavras fingidas da ficção não teriam a propriedade de montar no papel o escritor por elas responsável, como ocorre com as correspondências, implicando na aceitação ou sensação do efeito de fidelidade, embora isso nem sempre aconteça, já que "a carta tem algo de diário íntimo e tem algo da prosa de fícção" (SANTIAGO, 2006, p. 76).

Em "A escrita de si”, Foucault, citando as cartas de Sêneca, apresenta o gênero com noções relativas à prática reflexiva, não se contentando apenas ao aconselhamento ou à comunicação. Era por meio das chamadas "lições escritas" que Sêneca exercitava-se "em função de dois princípios que invoca frequentemente: que é preciso aperfeiçoar-se toda a vida e que a ajuda alheia é sempre necessária ao labor da alma sobre si própria (FOUCAULT, 1992, p. 145). E, mesmo quando não é o objetivo do remetente, “a carta não pode evitar o 
'eu'”, já que sua escrita “obriga a pensar em si para se posicionar e imitar a comunicação. Eis por que a correspondência às vezes representa um peso" (BOUZINAC, 2016, p. 128-129).

Nessa orientação, temos a carta como expressivo exemplo de exercício da escrita de si, tendo em vista que ela atua, "em virtude do próprio gesto da escrita, sobre aquele que a envia, assim como actua, pela leitura e releitura, sobre aquele que a recebe" (FOUCAULT, 1992, p. 145). Esse caráter, mesmo com as modificações referenciais e formais, será percebido mais contemporaneamente na publicação de diálogos epistolares, e talvez seja ele um dos motivos que tanto nos convidam à leitura. Em Graciliano, nos bilhetes, essas considerações não parecem tão evidentes, todavia a apreciação das outras cartas e de outros registros que se abrem a esse discorrer apontam para uma possível atitude do epistológrafo, nos pequenos textos, premido pela leitura censora e pelo essencial do momento.

Sobre essa face da correspondência, então, entendemos que a concepção de sujeito que o próprio sujeito possui de si em relação a um destinatário específico pode ser cambiante, em virtude da relativização do pronome reflexivo ("si") no ato da redação, situado em um tempo e lugar que podem interferir na constituição do epistológrafo, tópico relevante para os estudos biográficos e para os literários.

Em Memórias do cárcere, Graciliano Ramos faz referência a uma "cadeia invisível”, da qual as visitantes dos presos, destacadamente, constituíam elos ao possibilitarem a circulação de informações para além dos muros. O ambiente inspirava atenção com as palavras e com o grau de exposição do sujeito que as organizava. Dado o controle, abria-se espaço para a codificação: "Revistas improvisadas interceptavam frações da arriscada e numerosa correspondência; grande parte dissimulava-se nos vestidos, submergia-se na roupa íntima” (RAMOS, s.d., p. 231). Nos bilhetes de Cartas, não se percebe esse caráter cifrado, tampouco furtivo. Muito, é claro, perdeu-se com o referente da comunicação, mas muito ainda se aproveita, como o tom otimista dos dois primeiros escritos, que soa raro dada as circunstâncias: uma prisão sem processo, sem acusações formais. A seguir, a diversidade em relação ao gênero a que mais se aproxima.

Diante disso, por fim, ao tratar das diferentes posições que o epistológrafo pode assumir, Bouzinac pondera que a “consciência, quase sempre latente, dos 'papéis' que condicionam os cenários de escrita pertence a um não dito que se expressa por outras vias" (2016, p. 128). Assim, consideramos que a consciência da leitura e dos possíveis leitores 
interferiu não só no gênero, mas também no que nele consta e de que forma consta, fato percebido pelas mudanças estruturais e discursivas no que se refere aos objetivos da escrita. Levando em conta as ironias, constituinte da figura social do escritor, e as poucas palavras que não precisam brilhar mas dizer, encontramos nesses escritos sugestões e retratos, recortados, mas constituintes de um todo que se fragmenta em meio a outros testemunhos.

\section{Referências}

CANDIDO, Antonio. Ficção e confissão: ensaios sobre Graciliano Ramos. 3.ed. Rio de Janeiro: Ouro Sobre Azul, 2006.

FOUCAULT, Michael. "A escrita de si”. In: . O que é um autor? 2. ed. Lisboa: Passagens, 1992, pp. 129-160.

HAROCHE-BOUZINAC, Geneviève. Escritas epistolares. Tradução: Ligia Fonseca Ferreira. São Paulo: Editora da Universidade de São Paulo, 2016.

LIMA, Luiz Costa. “A libido da escrita nas Memórias do cárcere”. Folha de São Paulo. São Paulo, 09 março 2003. Mais! Disponível em: <http://www1.folha.uol.com.br/fsp/mais/fs0903200311.htm>. Acesso em 12 dez. 2016.

MORAES, Marcos Antonio de. Orgulho de jamais aconselhar: a epistolografia de Mário de Andrade. São Paulo: Editora da Universidade de São Paulo/Fapesp, 2007.

. "Epistolografia e crítica genética". Ciência e Cultura, São Paulo, v. 59, n.1, jan./mar. 2007. Disponível em: <http://cienciaecultura.bvs.br/pdf/cic/v59n1/a15v59n1.pdf.> Acesso em: 09 mai. 2015.

RAMOS, Graciliano. Cartas. 8. ed. Rio de Janeiro: Record, 2011.

Correspondência ativa - Arquivo Graciliano Ramos - Instituto de Estudos Brasileiros da Universidade de São Paulo, IEB-USP. Doado em 1980 por Heloísa Ramos. . Memórias do cárcere (vol. 1). São Paulo: Círculo do Livro, s. d. 
Conversas: Graciliano Ramos. Organização: Thiago Mio Salla, Ieda Lebensztayn. Rio de Janeiro: Record, 2014.

SANTIAGO, Silviano. "Suas cartas, nossas cartas". In: Ora (direis) puxar conversa! Ensaios literários. Belo Horizonte: UFMG, 2006. 